\title{
LAS MOTIVACIONES ASISTENCIALES EN DOS COFRADIAS LAICAS DEL SIGLO XV (BIAR Y ALCOY)
}

\author{
Mercedes Gallent Marco \\ Universidad de Valencia
}

La investigación que llevamos entre manos desde hace tiempo en torno al hecho asistencial en Valencia durante el siglo XV nos ha inducido a recorrer caminos, por llamarlos de alguna manera, ortodoxos: profesionales médicos, instituciones hospitalarias, epidemiología, etc. El presente trabajo, por contra, nos acerca a un campo más heterodoxo.

La heterodoxia consiste, fundamentalmente, en un doble aspecto: la extensión de nuestro campo de trabajo investigador a instituciones hasta el momento sólo marginalmente relacionadas con el problema asistencial y la hipótesis de que las cofradias - asociaciones, hasta ahora, primordialmente motivadas por razones religiosas - comienzan a justificarse, según evidenciará el estudio de los estatutos de Biar y Alcoy, básicamente en objetivos, motivaciones, sociales-asistenciales.

El marco para explicar y comprender este hecho parece estar encuadrado en el proceso evolutivo de la propia sociedad medieval hacia una modernización con unas notas de secularización y civismo donde los ciudadanos, aún dentro de modelos dominantemente religiosos, toman conciencia, acaso, de que tal secularización ha de pasar por la asunción de las responsabilidades sociales de sus propios miembros.

Con estos presupuestos, y en estas coordenadas, queremos analizar la estructura y objetivos de dos cofradias laicas, Biar y Alcoy, que estudiaremos con detalle, después de establecer panorámicamente la evo- 
lución: desde modelos fundamentalmente religiosos a los caracterizados por objetivos sociales como notas casi definitorias de las cofradías medievales.

\section{OBJETIVO RELIGIOSO VERSUS ASISTENCIAL EN LAS COFRADIAS MEDIEVALES:}

El estudio de las cofradías medievales es un tema que, por su amplitud, complejidad y diversidad en sus manifestaciones, ha constituido el objeto de algunos trabajos encaminados a sentar las bases para su correcto conocimiento e interpretación. Los investigadores han buscado una delimitación jurídica, un significado y han llegado a constatar una gran riqueza terminológica para su delimitación: collegio, schola, confraternitas, societas, términos connotadores de matices diferentes (1).

Siguiendo la obra de Giancarlo Angelozzi Le confraternite laicali, un'esperienza cristiana tra medioevo e età moderna (2), puede trazarse el interesante y significativo proceso del paso de las cofradías eminentemente religiosas, penitenciales, etc., a las cofradías que, a finales de

(1) ANGELOZZI, G., (1978), Le confraternitate laicali, un'esperienza cristiana tra medioevo e età moderna. Ed. Queriniana, Brescia. BOFARULL, P., (1876), Gremios y Cofradias de la antigua Corona de Aragón. Colección de Documentos Inéditos de la Corona de Aragón. Barcelona. CARCEL ORTI, M. ${ }^{a}$ M., Capitulos de Sta. Maria de la Sangre de Cullera (en prensa); en colaboración con TRENCHS ODENA, J., Notas en torno al estudio de las cofradias medievales y modernas: la cofradia de la lglesia del Santísimo Cristo del Sa/vador de Valencia, (1616-1618), (en prensa). DESCHAMPS, M., (1958), Les confreries du moyen age. Burdeos. LE BRAS, G., (1940-41), "Les confréries chrétiennes. Problèmes et propositions", Rev. d'histoire du droit française et étranger, 4 serie, $X \mid X-X X$, págs. 310-363; (1959), Institutiones ecclésiastiques de la chrétienté médiévale. Paris. MANSELLI, R., (1975), La religion populaire au Moyen Age. Problèmes de méthode et d'histoire. Institut d'estudes médiévales Albert Le Grand. Montreal. MARTINEZ MORELLA, V., (1974), Informe sobre las cofradias, hermandades $y$ otras especies de gentes colegiadas que se hallan en esta ciudad y su territorio, hecho por los Diputados de la misma, el señor correxidor de ella, en virtud de orden del Exmo. Señor Conde de Aranda, presidente del Consejo, a 28 de septiembre de 1770. Alicante. MEERSEMAN, G. G., (1977), Ordo fraternitatis. Confraternitate e pietà dei laici ne/ medioevo. Ed. Herder. Roma. RODRIGO PERTEGAS, J., (1922-23), Historia de la antigua y real cofradia de Ntra. Sra. de los Inocentes y Desamparados, de la venerada imagen y su capilla. Impr. Hijo de F. Vives Mora. Valencia. RUMEU DE ARMAS, A., (1981), Historia de la previsión social en España, (reedición). Ed. Albir, Barcelona.

Para una bibliografía más amplia sobre el contexto europeo remitimos a la obra de G. ANGELOZZI, (1978). Sobre cofradías de la antigua Corona de Aragón y concretamente sobre el País Valenciano, los artículos de la Dra. CARCEL ORTl, a la que agradecemos nos facilitase su consulta, ofrecen una extensa relación bibliográfica sobre el tema.

(2) ANGELOZZI, G., (1978), págs. 7-39. 
la Edad Media, sin dejar de ser religiosas irán acumulando datos de carácter secular en su funcionamiento y actuación.

La tendencia, remitiéndonos a sus orígenes, «a costituire assoziacioni con caratteri e fini religiosi non è evidentemente prerogativa o innovazione del cristianesimo, ché il cristianesimo stesso nasce e si sviluppa in un ambiente sociale che reagisce alla progressiva disgregazione delle strutture statali proprio attivando una fitta rete di assoziazioni di carattere religioso-professionale (eterie, collegia) che, dapprima osteggiate dalle autorità, finiscono con l'essere prima tollerate e poi incoraggiate ed utilizzate come suppletive e sostitutive dell'apparato pubblico in molteplici compiti cui esso non è più in grado di sopperire efficacemente» (3).

Tras estos inicios, las comunidades cristianas, se constituyen según Le Bras, sobre la imitación de "comportamenti e forme organizzative da collegi, corporazioni professionali, istituzioni municipali, ma li vivificano alla luce di un senso di fraternità sopranaturale, fondato sul concetto di corpo mistico» (4), y aparecerán en el siglo IV «società giuridica con leggi adattate alla capacità di masse piuttosto tiepide, i più zelanti formareno delle associazioni per soddisfare la loro pietà... Lo spiritu della fraternità primitiva sopravviveva. La sua parte migliore fu assorbita da una nuova forma associativa cristiana, minuziosamente ordinata, ben presto subordinata alla chiesa secolare: il monachismo" (5).

Esto que aparece como una tendencia irá, por lo que respecta al tema de las cofradías laicas, plasmándose en asociaciones específicas: "fossores" en Roma y Cirta, "parabolani" en Constantinopla, etc., cuya documentación puede encontrarse en algunos lugares importantes del Oriente Cristiano entre el siglo IV y el XIII. Los miembros de tales asociaciones se dedicaban al entierro de difuntos, cuidado de enfermos y, en algunos casos, practicaban duras actividades religiosopenitenciales.

Pero, al decir de Angelozzi, "Allo stato attuale delle conoscenze non si può dunque che affermare che le confraternite sono fenomeno tipicamente medievale, e che il tentativo di tracciare una linea di continuità fra di esse e associazioni cristiane dei primi secoli con caratteri vagamente simili non è altre che il meccanico riprodursi di un sottoprodotto della ottocentesca polemica che oppose «romanisti» e "germanisti» sul problema delle corigini di tanti aspetti della cultura e delle instituzioni

\footnotetext{
(3) ANGELOZZI, G., (1978), pág. 11.

(4) ANGELOZZI, G., (1978), págs. 11-12.

(5) ANGELOZZI, G., (1978), pág. 12.
} 
medievali» $(6)$, con lo qual «tentare di istituire un rapporto di analogia o addirittura di continuità fra tali forme associative e le confraternite medievali appare operazione in un caso rischiosa o nell'altro priva di fondamenti documentari» (7).

En el 852 Incmaro de Reims en los "capitula presbyteris data" presenta un primer tipo de asociaciones, vulgarmente llamadas "geldonie o confraternitate", y enumera sus actividades "raccolta di offerte per la chiesa, la manutenzione di essa e delle luminarie, l'aiuto scambievole fra i membri, le esequie dei confratelli defunti, la somministrazione di elemosine agli indigenti e tutte le altre opere de pietà" (8), características ya del medievo, a las que podemos añadir algunas más en el siglo $X$ en Italia (Nápoles, Módena...), todas ellas vinculadas estrechamente al ambiente y comunidades monásticas.

Un proceso similar, acompañado, sin duda, de una progresiva complejidad, se observará en la mayor parte de Europa, de forma que "già alla fine del XII secole i laici hanno svilupato forme associative e carattere religioso più complesse e meno legate alla iniziativa e alla direzione di religiosi” ( 9 ).

Los siglos XI y XII pusieron en marcha un movimiento de reafirmación del laicado con respecto a la salvación y su actitud religiosa al margen de los modelos monásticos, basados en un «complesso processo di trasformazione della societa sotto la spinta della espansione demografica, dopo secoli di stagnazione o di regresso, della rivitalizzacione del commercio e della circolazione monetaria, dell'espansione urbana e delle prime forme associative comunali, del poderoso moto de affrancamento di masse rurali cui la necessità di nuovi dissodamenti e di valorizzazione delle terre gia messe a coltura, imposta dalla accresciuta domanda, offre l'opportunità di rompere i legami di servitù personale e di costituire forme associative, spesso legate e comunità religiose che in tale processo di ripresa dell'agricoltura e di nuovi dissodamenti giocano spesso un ruolo non marginale» (10).

El siglo XIII afianzará este movimiento o despegue laico con respecto a los modelos estrictamente religiosos "sullo sfondo di un processo complessivo di diferenziazione e di articolazione del tessuto sociale che, anche sul piano del comportamento religioso, si traduce, per i laici, in una serie di suggestioni ed oportunità a sviluppare forme

(6) ANGELOZZI, G., (1978), pág. 13.

(7) ANGELOZZI, G., (1978), pág. 12.

(8) ANGELOZZI, G., (1978), pág. 13.

(9) ANGELOZZI, G., (1978), pág. 16.

(10) ANGELOZZI, G., (1978), pág. 18. 
associative autonome ed organizzate, costruite sul modello offerto da comuni, assoziazioni di arte, di mestiere e d'armi, universita..." (11). Además, tomarán fuerza con el apoyo que, en momentos delicados para la estructura eclesiástica, le prestarán dichas asociaciones laicas.

Todo esto hace que "nel XIII secolo le confraternitate laiche acquistano una diffusione e una differenziazione di caratteri e di scopi che ne fanno ormai una sede privilegiata per la vita spirituale dei laici e un vero e proprio tessuto connettivo del corpo sociale. La tendenza ad associarsi per assicurarsi protezione, difesa, assistenza, dignità sociale e ad attribuire una valenza religiosa a tutti gli aspetti dell'attività umana, tipiche della società e delia cultura medievale, fanno sì che la pietà dei laici dia vita ad una gamma assai ampia di nessi associativi, in cui i legami tra sacro e profano, fra autentica pietà ed esigenza pratica, sono talmente intrecciati da rendere impossibili distinzioni rigorose" (12).

A partir del gran auge del siglo XIII, y a pesar de la no urgencia de la lucha contra la subversión religiosa y social que había significado la herejía anteriormente, "le confraternite conoscono nei due secoli seguenti uno sviluppo pressoché continuo, che non sembra eccesivamente compromesso neppure dalla catastrofica peste del 1348. Tale capacità crescente di reclutamento e di attrazione si esplica sia per quel che riguarda le confraternitate di devozione nel pieno senso del termine, sia e soprattutto per quel che riguarda le confraternitate legate ad assoziacioni di arte e mestiere; anzi, nel caso di queste ultime, sembra che il complessivo scadere della capacita da parte delle corporazioni e arti di incidere profondamente nella vita politica, si traduca in un maggiore impegno nelle attività di mutua assistenza e di carità che sempre più divengono compito specifico della parallella organizzazione confraternale (13).

Esto justifica, quizás, el planteamiento de que "le confraternitate rappresentano la più capillarmente diffusa forma di assoziazione volontaria dell'Europa cristiana almeno a partire dal XIV secolo" (14), aunque parece difícil establecer la evolución cualitativa de estos movimientos laicos por la ausencia de trabajos monográficos y de síntesis parciales que nos ayuden a comprender el fenómeno con cierta globalidad, no obstante, se pueden anotar algunos fenómenos «di portata più generale e lacune linee di tendenza»:

(11) ANGELOZZI, G., (1978), pág. 19.

(12) ANGELOZZI, G., (1978), págs. 23-24.

(13) ANGELOZZI, G., (1978), pág. 30.

(14) ANGELOZZI, G., (1978), pág. 30. 
1. "dalla metà del XIV secolo in larghe zone della Francia, della Germania e dell'Inghilterra, si diffonda capillarmente l'istituzione di confraternite «luminarie» che rapidamente si istituzionalizzano e ampliano $i$ loro compiti in maniera tale da trasformaesi in ristretti consigli di gestione della parrochia e dei boni ad essa connesi" (15).

2. ${ }^{\circ}$ Reclutamiento restringido de los cofrades.

3. Persistencia del carácter devocional en Italia.

4. ${ }^{\circ}$ Mayor empeño en actividades caritativas y asistenciales en base a la situación socioeconómica de la Europa del momento.

5. Pérdida de espontaneidad y progreso en la estructuración de las mismas.

6. Gestión de algunas fundaciones caritativas.

7. Continuidad de las motivaciones religiosas para su fundación, pero gran importancia de las profanas, con evidentes riesgos y desviaciones que ponen en peligro la original fisonomía religiosa de las asociaciones, e introducen profundas alteraciones en su primitiva estructura.

8. Mayor valoración y fuerza de los. puestos directivos, así como tecnificación, jerarquizada y sofisticada de las funciones, marginando de los puestos relevantes a las personas provenientes de posiciones más humildes.

9. Mayor influencia en el ámbito de la sociedad y consecuente conflictividad entre los miembros de las cofradías o de éstos con el poder establecido que, buscando el control de las asociaciones, intenta eliminar su autonomía «per sopperire alle ancora carenti strutture fiscali e finanziarie, tendono ad allargare il propio controllo sulle confraternite, facendo leva su progetti, talora pretestuosi, di ristrutturazione e accentramento delle fondazioni caritative" (16).

$10 .^{\circ}$ Cierto cambio en la composición social de los miembros pasando de la prevalencia social de la media burguesía a la aristocracia y a la clase dirigente, sobre todo en el siglo XV, no tanto con respecto a la pertenencia cuanto a la ocupación de puestos claves.

11. Relación bastante estrecha de las órdenes mendicantes y las cofradias por razones diversas.

12. Las características, a pesar de todo lo anotado de las cofradías laicas, es que siguen aún, en los siglos XIV y XV, tipificadas en los modelos de movimientos penitenciales y cofradías disciplinarias, si bien irán alcanzando unos límites de normalidad, puesto que salvo las

(15) ANGELOZZI, G., (1978), pág. 31.

(16) ANGELOZZl, G., (1978), págs. 32-33. 
exageraciones del siglo XIV, la penitencia será un elemento más de religiosidad, pero no exclusivo, quizás como "frutto più maturo di tale impegno del laicato pio e della tensione spirituale degli ultimi anni del 400 e dei primi decenni del 500 è la fioritura in Italia degli oratori del divino amore, che si inseriscono agevolmente nel secolare filone della pieta laica confraternale, con rinnovanti accenti nella rigorosita degli impegni di vita cristiana adottati dai confratelli nel fervore della attività caritativa e nella austerità delle pratiche ascetiche e penitenzialli consumate in spirito di umilta e di amore, in una prospecttiva di riforma e di conversione personale che vuole essere esplicito contributo alla riforma della chiesa» (17).

\section{DOS COFRADIAS LAICAS EN EL ANTIGUO REINO DE VALENCIA (SIGLO XV)}

En conexión con lo anotado anteriormente iniciamos el estudio de dos cofradías referidas a dos poblaciones del antiguo Reino de Valencia, Biar y Alcoy (18), aprobadas por el rey Don Fernando en la misma fecha, 4 de agosto de 1494, y que presentan características similares respecto a su razón de ser y contenido de sus capítulos.

Basándonos en el análisis detenido de la documentación que poseemos (los estatutos de tales cofradías), consideramos operativo centrar su estudio en los siguientes puntos:

- Carácter de las cofradías.

- Causas de su formación.

- Reglamento interno de las cofradías.

\subsection{Carácter de las cofradias:}

Resalta el carácter eminentemente laico de estas cofradías frente al carácter religioso que conforma a la mayoría de las cofradías medievales por tres motivos fundamentales:

- El estado laico de sus promotores: el justicia, jurados y consejo de las villas "Cum pro parte fidelium nostrorum justitie juratorum et concilii ville de Biar/Alcoy", aunque no se observa dato alguno que prohiba la adscripción a las cofradías de algún religioso.

- La autoridad que aprueba su constitución como tales: la

(17) ANGELOZZI, G., (1978), págs. 38-39.

(18) REAL CANCILLERIA, reg. 309, fol. 233 bis v. ${ }^{\circ}-238 r .^{\circ}$ (doc. $r^{\circ} 1$ ); fol. $238 r .^{\circ}-242 v .^{\circ}$ (doc. n. ${ }^{\circ}$ 2). A.R.V. 
real (19). Autoridad con poder suficiente como para imponer determinadas objeciones a los estatutos, tales como la presencia de un delegado suyo en las reuniones de los cofrades (Biar: cap. 10 y 11 ; Alcoy: cap. 9 y 10).

- Las razones exclusivas de su fundación: enterrar a los difuntos y prestar ayuda a los enfermos y necesitados, a las que se subordinan todas las demás.

\subsection{Causas de su formación:}

Precisa el preámbulo de ambos documentos que el justicia, jurados y consejo de estas poblaciones alegan cómo "la vestra vila de Biar $(0$ Alcoy) que és en lo regne de València, és en numero de trecents vehins (en Alcoy no se especifica), e de cascún dia augmenta, e los pobladors de aquella o lo major numero dels dits vehins són lauradors que cascún dia van a ses heretats e masades, e moltes vegades se esdevé que algú mor en la vila, e per no haver en aquella confraria alguna los morts no són soterrats ab aquella honor e reverencia que deurien ésser soterrats». Consideran, además, que "los pobres, axí en ses necessitats com en les obsequies de aquelles serien honrats, e en ses malalties per los cofrares subsegüents".

Las causas de fundación son, en definitiva, esencialmente sociales pese a que vayan teñidas de un matiz religioso mediatizado por un nuevo sentido de la caridad que se manifestará plenamente en años posteriores; conectando con lo apuntado por Giancarlo Angelozzi «Un altro aspetto più generale caratterizzante è il maggiore impegno delle confraternitate nelle attività caritative ed assistenziali, stimolato anche

(19) Cfr. RUMEU DE ARMAS, A., (1981). Este autor, al hablar en el capítulo VIII de su obra dedicado a "La organización de las cofradias y su sistema de previsión" sobre la formación de éstas dice: "Los individuos que acordaban establecer una hermandad se reunían en día y lugar determinado para establecer las bases del acuerdo... Sobre ellas algún clérigo o letrado ... establecía la regla, ordenanza o estatuto".

Más adelante, al tratar sobre la autoridad que debía refrendar tales asociaciones añade "... no hay indicios de que fuese para ello necesario la aprobación eclesiástica y menos la real. En cambio si tenían que contar como era natural, con el asentimiento de la iglesia o convento que iba a recibirles.

Alguna vez se prescribió, sin embargo, la aprobación episcopal...», “En cuanto a la aprobación real -especifica-, en un principio no era necesaria, ni lo fue tampoco nunca obligatoria en las regiones de la Corona de Aragón, cuando las cofradías se limitaban a fines exclusivamente religiosos o benéficos. Sin embargo, para dar más fortaleza, prestigio y autoridad a sus ordenanzas era costumbre el que las cofradias acudiesen pidiendo revali. dación y confirmación a los reyes, y gracias a ello conocemos la mayor parte de las ordenanzas, que por ese sólo hecho quedaron registradas en los Archivos reales", págs. 118119. 
dalla crisi economica che attanaglio l'Europa della seconda metà del XIV secolo ed al conseguente aggravarsi del problema del pauperismo, che si configura ormai come fenomeno endemico e di massa; un impegno che va perdendo i primitivi caratteri di estemporaneità, di libero e discrezionale esercicio di pietà, pers assumere forme più strutturate, continue e tecnicamente complesse" (20).

\subsection{Reglamento interno de las cofradías:}

Los capítulos del reglamento versan sobre diversos aspectos y abarcan temas relativos a derechos y deberes de sus socios, actividades religiosas y sociales, administración, etc. Facilitamos su comprensión agrupándolos en los siguientes apartados:

- actividades religiosas

- actividad benéfico-social

- cuestiones administrativo-económicas.

\subsubsection{Actividades religiosas:}

Incluimos en este punto los capítulos que atañen a cuestiones relativas a la advocación de las cofradias, obligatoriedad de asistencia a celebraciones litúrgicas, plegarias, etc.

2.3.1.1. Advocación de las cofradías: Ambas cofradías se fundan bajo la advocación de la virgen María, según especifican el preámbulo "supliquen humilment a vostra altesa sia de sa clemencia e merce donarlos licencia e facultat de poder instituyr la dita confraria sots invocació de nostra senyora la gloriosa Verge Maria» y el primero de éstos (Biar: cap. 1; Alcoy: cap. 1).

2.3.1.2. Lugar de reunión: Según se deduce de la lectura de los textos carecen de un lugar de reunión propio, por ello se valen de un local religioso "la capella major o la sglesia de la Verge Maria de la dita vila" (Biar: cap. 7; Alcoy: cap. 6).

2.3.1.3. Celebraciones y actos litúrgicos:

a) Festividades estipuladas: Cuatro son las consideradas de mayor relevancia, todas coincidentes con celebraciones importantes en el culto mariano: «la Annunciació de la Verge Maria de març» (día de la Encarnación, 25 de marzo), "lo dia de la Assumpció de Nostra Senyora" (15 de agosto), "lo dia de la Verge Maria de setembre" ( 8 de septiembre) y "lo dia de la Expectació de Nostra Senyora" (día de la Presentación, 2 de febrero) (Biar: cap. 11; Alcoy: cap. 10).

(20) ANGELOZZI, G., (1978), pág. 31. 
b) Procesiones: Sólo en una ocasión se estipula uno de estos actos: el día de la Asunción de la Virgen antes de los oficios litúrgicos se llevará a cabo una procesión solemne «per los lochs que s'acostumen"; en el caso de Biar se especifica aun más "per los lochs que s'acostumen fer les processons del cos de Jesus"; a dichos actos deberán acudir todos los cofrades llevando cirios (Biar: cap. 12; Alcoy: cap. 11).

c) Asistencia a misas: Unicamente se precisa la obligatoriedad de asistencia a este acto en la cofradía de Biar, los sábados todos sus socios estarán "obligats en for de consciencia" a acudir a la misa de la Virgen que se celebrará por la mañana en la iglesia mayor, en la "capella de n'Anthoni Gil quondam sots invocació de la senyora Sancta Anna». Dicha obligación será ineludible a no ser que justifiquen la no asistencia en base a causa justificada (Biar: cap. 5).

d) Plegarias: Sólo se estipula el rezo de unas determinadas oraciones $y$ een for de consciencia" dos días a la semana. Los viernes cinco Padrenuestros y siete Avemarías en honor de la Pasión del Señor. Los sábados siete Padrenuestros y siete Avemarías en recuerdo de los siete gozos de la Virgen (Biar: cap. 6; Alcoy: cap. 5).

\subsubsection{Actividad benéfico-social:}

La función determinante de estas asociaciones es, en primer lugar, prestar ayuda a todas aquellas personas, cofrades o no, en cualquier necesidad material, sobre todo en caso de enfermedad "sia judat e subvengut axí en malalties com en altres necessitats", siempre con conocimiento de los mayorales y según posibilidades de la cofradía (Biar: cap. 8; Alcoy: cap. 7).

En segundo término y como motivo principal que aducían los promotores para fundar las cofradías objeto de nuestro estudio «...per quant la major part dels vehins de la dita vila son lauradors, e moltes vegades, speriencia fa testimoni, que al soterrar de algú no haver-hi aui.I soterre...", se manda acompañar a los difuntos durante las exequias y proporcionarles un entierro digno.

En función de ello, todos los cofrades serán convocados «quant morrà algún cofrare o algún pobre morrà en lo spital» «ab só de campaneta... o ... ab veu de andador", a fin de que asistan a las exequias y acompañen al difunto, portando cirios, desde su casa a la iglesia y desde ésta al cementerio hasta que sea inhumado.

Si por alguna causa no acudieran se les penalizaría con "dos diners" en caso de día festivo o domingo y con uno si fuera día de labor. 
Tan sólo si aducían una causa justificada podrían ser perdonados o modificada la sanción impuesta, pero a tenor de lo que consideraran los mayorales (Biar: cap. 2 y 3 ; Alcoy: cap. 2 y 3 ).

\subsubsection{Cuestiones administrativo-económicas:}

Comprende este apartado todos aquellos capítulos que atañen a la organización del cuadro rector de la cofradía, su forma de elección, etc., así como los que indican fuentes de ingresos, su administración... 2.3.3.1. Cuerpo rector: Puesto que las cofradías son de nueva creación y carecen de una estructura dirigente, en sus capítulos se estipula que, una vez obtenida la licencia real para su constitución, sean elegidos por el justicia y jurados de las villas atres bons homens, vehins de la dita vila" para desempeñar el cargo de "mayorals", y otros diez hombres para que sean los "conseyers de los mayorales.

A partir de estos nombramientos iniciales, y en adelante, se seguirá el sistema electivo, designando cada uno de los tres mayorales a cuatro cofrades y el escriva a uno; de los trece candidatos se sacarán tres a suerte, que serán mayorales, siendo los diez restantes consejeros.

La renovación de estos cargos será anual, procediéndose a su elección la víspera de la Asunción, no comportando su desempeño salario alguno (Biar: cap. 13 y 15; Alcoy: cap. 12 y 14).

2.3.3.2. Admisión de socios y libros de matrícula: Los capítulos no estipulan ningún requisito especial para la admisión de cofrades relativo a clase social, estado, o condición hombre/mujer (los estatutos citan repetidas veces a las "confraresses", "que cascún confrare o confraressa quant iràn al soterrar...", "que quant tots los confrares $e$ confraresses puix ab só de campaneta seràn convocats..."), aunque ignoramos si las mujeres podían desempeñar algún cargo rector, ya que al hablar de la elección de los mismos, los capítulos exigen siempre que sean elegidos «bons homens», expresión que difícilmente puede aplicarse, por extensión, a las mujeres.

Los únicos que podían admitir nuevos cofrades eran los mayorales, siendo expresado tal punto de modo tajante por los capítulos "no sia admés a confrare ningù sino per los dits majorals", estipulándose además la cuota inicial de ingreso: tres sueldos, que se depositarán en la caja de la cofradía.

Todos los cofrades deberán ser anotados en un libro, en poder del escriva, a fin de tener una relación exacta de los afiliados, tachándose el nombre de éstos a su muerte (Biar: cap. 9 y 14; Alcoy: cap. 8 y 1). 2.3.3.3. Local social y reuniones: Tal como apuntamos anteriormente, el lugar de reunión era la capilla mayor de la iglesia de las localidades respectivas. 
Podrían reunirse "tantes quantes vegades serà necessaria per obs de la dita confraria", debiendo estar presente un oficial real, si bien, en las vísperas de las fiestas ya señaladas, Encarnación, Asunción, Virgen de septiembre y Presentación, están estipuladas formalmente, contando también con la presencia del representante del rey.

El fin de dichas reuniones será «parlar de las coses concernents la utilitat de la confraria o necessitats de aquella" (Biar: cap. 10 y 11; Alcoy: cap. 9 y 10).

2.3.3.4. Economía: Desconocemos si las cofradías contaron con alguna donación, legado, etc. que viniera a conformar su patrimonio económico.

Unicamente podemos constatar que sus fondos, siempre a partir de la documentación estudiada, provenían de:

- cuotas de ingreso: 3 sueldos (Biar: cap. 9; Alcoy: cap. 8);

- dinero que se daba en las cuatro festividades reseñadas: 2 dineros (Biar: cap. 11; Alcoy: cap. 10);

- dinero que deben legar los cofrades: 3 sueldos (o mayor cantidad, a voluntad). Si fuera pobre se le dispensaría;

- dinero que debe entregar quien "en la sua fi" quisiera ingresar en la cofradia: 10 sueldos, pudiendo también aumentar la cantidad (Biar: cap. 4; Alcoy: cap. 4);

- dinero proveniente de las sanciones económicas impuestas a los cofrades que no cumplieran sus obligaciones como tales: quienes no acudan a los entierros habiendo sido convocados: 2 dineros si es festivo o domingo; 1 dinero si es día de trabajo, cantidades como ya dijimos que podrán ser modificadas a juicio de los mayorales siempre que se justifique debidamente la ausencia (Biar: cap. 2; Alcoy: cap. 2).

Todo el numerario así obtenido era guardado en la caja de la cofradía, caja que tenía tres llaves diversas y que poseían respectivamente cada uno de los tres mayorales, no pudiéndose abrir "per ninguna necessitat urgent o voluntaria" sin la presencia de los diez consejeros (Biar: cap. 9; Alcoy: cap. 8).

Así mismo, se prohibe tajantemente, quizás para no menguar los reducidos medios económicos y "ob reverentiam Dei», que mayorales y consejeros "tinguen salari algú" y que se gaste en "dinars, ni sopars, ni altres col.lacions" (Biar: cap. 15; Alcoy: cap. 14).

Los mayorales deberán llevar además un "libre de dates e rebudes", dando cuenta de todo su ejercicio a los mayorales entrantes en presencia de los consejeros al día siguiente de la fiesta de la Asunción, entregándoles «claus, caxa, diners, robes, joyes e altres coses ... ab inventari» (Biar: cap. 18; Alcoy: cap. 17).

2.3.3.5. Interpretación de los estatutos y remodelación de éstos: Por 
último, se tiene en cuenta la posibilidad de que los capítulos presenten "paraules ambigües e dubtoses", debiendo entonces exponerlo los mayorales a un perito en leyes a fin de que interprete su correcto sentido (Biar: cap. 16; Alcoy: cap. 15).

Además, contaron con que la acción del tiempo podría acarrear algún desfase, planteando la necesidad de rehacerlos o de añadir nuevas cláusulas por parte de los cofrades, necesitando siempre "la auctoritat e decret del governador del Regne de Velencia o del lochtinent de governador... e no sens decret de aquell o de l'altre d'ells" (Biar: cap. 17; Alcoy: cap. 16).

1494, agosto 4. Segovia

El rey D. Fernando aprueba los capitulos presentados por el justicia y jurados de la villa de Biar para la fundación de una cofradia bajo la advocación de la Virgen María.

A.R.V., Real Cancilleria, reg. 309 , fol. 233 bis v. ${ }^{\circ}-238$ r. $^{\circ}$

\section{JUSTITIE JURATORUM ET CONCILII VILLE DE BIAR}

Nos Ferdinandus et caetera. Cum pro parte vestrorum fidelium nostrorum justitie juratorum et concilii ville de Biar Prefati nostri Valentie regni fuerint coram maiestate nostra oblati et reverenter presentatis supplicatio et capitula seriei sequentis:

Molt alt e molt poderós Princep, Rey e Senyor, la vostra vila de Biar que és en lo regne de València és de numero de trecents vehins, e de cascún dia augmenta, e los pobladors de aquella o lo major numero dels dits vehins són lauradors que cascún dia van a ses heretats e masades, e moltes vegades se esdevé que algú mor en la vila, e per no haver en aquella confraria alguna los morts no són soterrats ab aquella honor e reverència que deurien ésser soterrats, havent-hi alguna confraria en la dita vila serien fetes les sepultures dels que morien més honrades e més a laor de nostre Senyor Déu que huy no són, e senyaladament los pobres, axi en ses necessitats com en les obsequies de aquelles serien honrats, e en ses malalties per los confrares subsegüents. E per co, Senyor molt excel.lent, los justícia, jurats e consell de la dita vila de Biar supliquen humilment a vostra altesa sia de sa clemencia e merce donar-los licencia e facultat de poder instituyr la dita confraria sots invocació de nostra senyora la gloriosa Verge Maria, e 
per fundació de la dita confraria offiren e presenten a vostra altesa los capítols infrasegüents, los quals son ordenats per a fundació de aqueIla, suplicant encara a vostra real majestat molt humilment li placía atorgar la dita confraria ensemps ab los dits capítols a laor de nostre senyor Déu e de la dita gloriosa mare sua sempre Maria, e servey seu e de vostra altesa et licet et caetera. Altissimus et caetera. Los quals capítols són del tenor $/ /\left[\mathrm{fol} .234 r .^{\circ}\right]$ següent:

Capítols per obs de la confraria fahedora en la vila de Biar sots invocació de la gloriosa Verge Maria:

[1] Primo, sia de nou instituhida, construyda e fundada una confraria en la vila de Biar sots invocació de la Verge gloriosa Maria, mare e senyora nostra. Plau al Senyor Rey.

[2] Item, que quant la major part dels vehins de la dita vila són lauradors, e moltes vegades, speriencia fa testimoni, que al soterrar de algú, per no haber-hi qui.l soterre, que quant morrà algún confrare o algún pobre morrà en lo spital, con aquell sia hagut per confrare, que tots los confrares e confraresses puix, ab só de campaneta, seràn convocats, o en altra manera, ab veu de andador, sien tenguts de anar al soterrar del dit confrare o del que morrà en lo spital, e acompanyar lo cos al simenteri, e los confrares o confraresses que axí convocats al dit soterrar no iràn, si serà dia de festa colent, o diumenge, que cascú de aquells paguen dos diners los quals vinguen a la caxa de la dita confraria per a cera e altres necessitats de la dita confraria, e si serà dia fahener paguen un diner, si ja los dits confrares justa scusació no daràn coneguda per los majorals de la dita confraria e aquells puixen absolre o moderar segons la scusació quel.s doràn. Plau al Senyor Rey.

[3] Item, que cascún confrare e confraresa quant iràn al soterrar e acompanyar algún cos de confrare hajen de portar lum encesa de la casa de hon potaràn lo cos fins a la yglesia, e de la yglesia fins al simenteri, e fins lo $/ /\left[\right.$ fol. $\left.234 \mathrm{v}^{\circ}{ }^{\circ}\right]$ cos sia soterrat, e en la missa tot lo sacrat Evangeli o de la sacra fins haver consumit lo sacrat cos de Jesus nostre redemptor. Plau al Senyor Rey.

[4] Item, que com algún confrare morra haja de dar de sos bens a la dita confraria tres sous, si major suma no y voldrá dar, e si serà pobre que no pague res, coneguda la dita pobrea per los majorals de aquella, e si algú, en la sua fi, voldrà entrar en la dita confraria, pague deu sous si major suma no y voldrà donar. Plau al Senyor Rey.

[5] Item, que cascún dissapte tots los confrares de la dita confraria sien tenguts e obligats en for de consciencia anar a la missa matinal de la Verge Maria que.s diu en la yglesia major de la dita vila, en la capella den'Anthoni Gil, quondam sots invocació de la senyora Sancta Anna, hon cascún dissapte de matí se celebra missa cantada ab diaqua e sot 
diaqua, e cascún confrare porte son ciri lo qual hage de cremar o tenir lum tot lo sagrat Evangeli e de la sacra fins haver consumit lo cos sagrat de Jesus salvador, nostre Senyor. Si la justa scusació no tendràn. Plau al Senyor Rey.

[6] Item, que cascún divendres tots los confrares en for de consciencia sien tenguts dir cinch Pater Nostres e set Ave Maries a honor e reverencia de la passió de Jesus nostre Senyor, per les ànimes dels confrares, e cascún disapte set Pater Nostres e set Ave Maries a honor e reverència dels set goigs de nostra senyora la gloriosa Verge Maria. Plau al Senyor Rey.

[7] Item, que la casa dedicada per la dita confraria hon se hajen ajustar los confrares per a les coses necessaries e concernents $/ /$ fol. $235 r^{\circ}{ }^{\circ}$ la conservació, utilitat e augment de la dita confraria, e tenir caxa, joyes, robes e altres coses necessaries a la dita confraria sia la capella major o yglesia de la Verge Maria de la dita vila en lo loch pus decent hon la dita confraria és fundada sots la dita invocació per què sia augment de la dita sglesia. Plau al Senyor Rey.

[8] Item, si algún confrare serà constituhit en necessitat e serà que a sa tal necessitat no puixa complir que la dita confraria, a coneguda dels majorals de la dita confraria e de deu consellers de dita confraria, sia ajudat axí en malaltia com altres necessitats juxta les facultas de la dita confraria. Plau al Senyor Rey.

[9] Item, que tos aquells qui voldràn ésser confrares de la dita confraria per obs de les necessitats de aquells hajen de pagar e paguen de entrada tres sous cascún confrare, les quals quantitats vinguen e sien possades en una casa, la qual caxa haja de tenir tres claus diverses, $\mathbf{e}$ cascuna clau tingua son majoral, la qual caxa no.s puga abrir per ninguna necessitat urgent e voluntaria sens presencia de deu confrares de la dita confraria que seràn elets per consellers dels dits majorals e la major part de aquells. Plau al Senyor Rey.

[10] Item, que cascún any se puixen ajustar en la yglesia major de la Verge Maria //[fol. $235 \mathrm{v}$. ${ }^{\circ}$ de la dita vila los confrares de la dita confraria tantes quantes vegades serà necessari per obs de la dita confraria, si tal necessitat hi acorrerà en beneffici de aquella e laor de nostre senyor Déu e servici de sa altesa del Rey nostre senyor, convocant aquella los majorals de la dita confraria com en altra manera. Plau al Senyor Rey, pus hi sia en la dita congregació un official real.

[11] Item, que quatre festes del'any, ço es, de la Annunciació de la Verge Maria de març, lo dia de la Assumpció de Nostra Senyora, lo dia de la Verge Maria de setembre e lo dia de la Spectació de Nostra Senyora, aprés les vespres dites tots los confrares se hajen de ajustar en la dita sglesia de la Verge Maria hon puixen parlar de les coses 
concernents la utilitat de la dita confraria e necessitats de aquella, e cascún confrare haja de dar les dites quatre festes dos diners cascuna de les dites festes, les quals quantitats sien posades en la dita caxa per obs de la conservació de la dita confraria segons en lo desús dit noven capitol se conté parlant de la dita caxa. Plau al Senyor Rey, peró que en lo dit ajust haja entrevenir un official real como dit és.

[12] Item, que lo dia de la Assumpció de la Verge Maria, ans del offici sia feta processó solemne per los lochs que s'acostumen fer les processons del cos de Jesus ab tots los confrares ab ciris cremants en les mans. Plau al Senyor Rey.

[13] Item, que obtesa la licencia de la real majestat per a fundar la dita confraria $/ /\left[\mathrm{fol}, 236 \mathrm{r} .{ }^{\circ}\right]$ que sien elets per los justícia e jurats de la dita vila tres bons homens vehins de la dita vila en majorals de la dita confraria, e per los dits justícia e jurats sien elets deu bons homens dels confrares de la dita confraria per a consellers dels dits majorals, e en les altres eleccions fahedores d'aquí avant dels dits majorals sia servada aquesta forma, co és, que la vespra de la Asumpssió de la Verge Maria per los majorals de la dita confraria sien elets treze bons homens, e de sana consciencia, a saber es, quatre per cascú dels dits majorals, e hun per lo scriva de la dita confraria, los quals, ans de fer la dita elecció, en presencia dels dits deu consellers de la dita confraria juren que farán bona elecció segons Déu e sa consciencia, e feta la elecció de les dites treze persones dels dits confrares, los noms de aquells sien posats en redolíns de cera e closos posats en un bací plé d'aygüa, e sien trets del dit bací tres dels dits redolíns per hun infant, e aquells sien majorals aquells any, e los deu que restaràn en lo dit bací sien consellers de aquells en lo que los dits majorals los hauran menester. $E$ axí se segueixcha perpetualment. Plau al Senyor Rey.

[14] Item, que tots los confrares sien scrits en un libre, e aquell stigua en poder del scriva de la dita confraria, per què quant algú voldrà entrar en la dita confraria sia continuat escrit en lo dit libre, e si algú morirà [fol. $236 \mathrm{v}^{\circ}{ }^{\circ}$ ] li sia feta la creu, empero no sia atmes a confrare ningú sinò per los dits majorals, e aquells presents sia scrit en lo dit libre, e axí se haurà notícia dels dits confraes quants seràn. Plau al Senyor Rey.

[15] Item, que los dits majorals no hajen salari ningú, ni los consellers, sino que ob reverentiam Dei tinguen la dita majordomia, ni puixen donar ni guastar en dinars ni sopars ni col.lacions cosa alguna sino tantum en necessitats en la forma ja desús dita. Plau al Senyor Rey.

[16] Item, si en los presents capítols hi havia algúns capítols ab paraules ambigües o dubtoses, aquelles sien interpretades e declarades per los majorals a consell de hun doctor de bona e sana consciència. Plau al Senyor Rey. 
[17] Item, perque lo succés del temps mostra la necessitat de les coses, si en los presents capitols se haurà de smenar alguna cosa o de nou fer, o justar alguns altres capítols, o comutar en millor, que sien en servey de nostre senyor Déu e conservació de la dita confraria, los dits confrares los puixen fer comutar, ajustar e de nou smenar ab auctoritat e decret del governador del Regne de València o del lochtinent de governador de ça lo riu de Xùquer, e no sens decret de aquells o de l'altre d'ells. Plau al Senyor Rey.

[18] Item, que los dits majorals sien tenguts de fer libre de dates e de rebudes, e hajen de dar compte e rahó de sa administració cascún any lo sendemà del dia de la Assumpció de la Verge Maria //[fol. $\left.237 r^{\circ}\right]$ als nous majorals en presencia dels deu consellers de la dita confraria, e dat lo dit compte reten les claus, caxa, diners, robes, joyes e altres coses de la dita confraria als dits nous majorals ab inventari, e axí se seguescha de cascún any de huns en los altres perpetualment. Plau al Senyor Rey.

Quequidem capitula preinserta per vos nos diligenter visa et recognita consulto decretavimus et modifficavimus ipsa ut in pede unius cuisque ipsorum capitulorum annotatum est fuerit que ex inde pro parte vestrum predictorum justitie juratorum et concilii dicte ville de Biar maiestate nostre humiliter supplicatum ut ipsa capitula et ordinationes in eisdem contentas et expressas laudare approbare confirmare et auctorizare de nostri solita benignitate dignaremur. Nos vero propicientes quantum confert utilitati rei publice huius ville ut in prospero reformetur et conservetur. Id circo supplicationi vestre predicte benigniter inclinati volentes quod preinserta capitula omnia et singula et in eis et eorum quolibet contenta teneantur et observentur ab omnibus iuxta responsiones et decretationes nostras in pede uniuscuiusque dictorum capitulorum annotatas.

Tenori presentis nostri privilegii perpetuo firmiter valituri scienter deliberate et consulto capitula preinserta et omnia et singula in eis eorum quolibet contenta iuxta decretationes responsiones et modiffi [fol. $237 \mathrm{v}^{\circ}$ ] cationes in pede uniuscuiusque eorum continuatas ut superius continetur laudamus approbamus confirmamus et concedimus aisque auctoritatem nostram impendimus pariter et decretum. Illustrissimo propterea Joanni principi Asturiarum et Gerunde primogenito nostro carissimo ac in omnibus regnis et terris nostris post felices et longevos dies inmediato heredi et succesori sub paterne benedictionis obtentu dicimus gerentiviroque vices nostri generalis gubernatoris in dicto Valencie regno baiulo generali justitiis juratis ceterisque demum universis et singulis officialibus et subditis nostris in eodem regno constitutis et constituendis dictorumque officialium locuntenentibus presentibus 
et futuris dicimus precipimus et iubemus sub ire et indignationis nostre in cursu penaque florenorum auri Aragonum duorum mille a secus agentis bonis exigendorum nostrisque inferendirum eraiis quatenus predicta capitula et omnia et singula in eis et ipsorum quolibet contenta teneant firmiter et observent tenerique et obsenvari faciant inviolabiliter per quoscumque et non contrafaciant vel veniant ratione aliqua sine causa pro quanto dicto illustrissimus princeps nobis obedire ceterisque autem officiales et subditi nostri gratiam nostram caram habent iramque et indignationem nostras ac preapositam penam cupiunt non subire.

In cuius rei testimonium presentem fieri iussimus nostro comuni sigillo in pendenti munitum.

Datum in civitate Segovie quarto die mensis $/ /\left[\mathrm{fol} .238 \mathrm{r.}^{\circ}\right]$ augusti anno a Nativitate Domini millesimo quadringentesimo nonagesimo quarto regnorumque nostrorum videlicet Sicilie anno vicesimo septimo Castelle et Legionis vicesimo primo Aragonum sexto decimo Granate autem tercio.

Yo el Rey

Dominus Rex mandavit mihi Ludovico Gonçales vissa per Albanell regis cancellarii et generalem thesaurarii et Malferitum de regio consilio et per A. Bonet pro generali conservatore.

Probata

1494, agosto 4. Segovia

El rey D. Fernando aprueba los capitulos presentados por el justicia y jurados de la villa de Alcoy para la fundación de una cofradia bajo la advocación de la Virgen María.

A.R.V., Real Cancilleria, reg. 309, fol. 238 r. $^{\circ}-242$ v. $^{\circ}$

JUSTITIE JURATORUM ET CONCILII VILLE DE ALCOY

Nos Ferdinandus et caetera. Cum pro parte vestrorum fidelium nostrorum justitie juratorum et concilii ville de Alcoy prefati nostri Valentie 
regni fuerunt coram maiestate nostra oblati et reverenter presentati suplicatio et capitula seriei sequentis:

Molt alt e molt poderós Princep, Rey e Senyor. La vostra vila de Alcoy que és en lo regne de València és de numero de [hueco]// [ $\mathrm{fo} /$. $238 \mathrm{v}^{\circ}{ }^{\circ}$ vehins, e de cascun dia augmenta, e los pobladors de aquella o lo major numero de aquells són lauradors que cascún dia van a ses heretats e masades, e moltes vegades se sdevé que algú mor en la vila, e per no haver en aquella confraria alguna los morts no són soterrats ab aquella honor e reverència que deurien ésser soterrats bé, $e$ havent-hi alguna confraria en la dita vila serien fetes les sepultures dels que morien més honrades e més a laor de nostre Senyor Déu que vuy no són, e senyaladament los pobres, axí en ses necessitats com en les obsequies de aquelles serien honrats en ses malalties per los confrares subsegüents. $E$ per ço, Senyor molt excel.lent, los justícia e jurats e consell de la dita vila de Alcoy suppliquen humilment a vostra altesa sia de sa clemencia e merce donar-los licencia e facultat de poder instituhir la dita confraria sots invocació de nostra senyora la gloriosa Verge Maria, e per a fundació de la dita confraria offiren e presenten a vostra altesa los capítols infrasegüents, los quals són ordenats per fundació de aquella, supplicant encara a vostra real majestat molt humilment li placía atorgar la dita confraria ensemps ab los dits capítols a laor de nostre Senyor Déu e de la dita gloriosa mare sua sempre Maria, a servey seu e de vostra altesa et licet et caetera. Altissimus et caetera. Los quals capitols són del tenor següent:

Capítols per obs de la confraria fahedora en la vila de Alcoy sots invocació de la gloriosa verge Maria:

[1] Primo, que sie de nou instituyda, construyda e fundada una confraria en la vila de Alcoy sots invocació de la gloriosa Verge Maria //[fol. $239 r .{ }^{\circ}$, mare e senyora nostra. Plau al Senyor Rey.

[2] Item, que per quant la major part dels vehins de la dita vila són lauradors, e moltes vegades, speriencia fa testimoni, que al soterrar de algú no haver-hi qui.l soterre, que quant morrà algún confrare o algún pobre morrà en lo spital, com aquell sie hagut per confrare, que tots los confrares e confraresses puix ab só de campaneta seràn convocats, o en altra manera, ab veu de andador, sien tenguts de anar al soterrar del dit confrare o del que morrà en lo spital, e acompanyar lo cos al simenteri, e los confrares e confraresses que axí convocats al dit soterrar no iràn, si serà dia de festa colent o diumenge, que cascú de aquells paguen dos diners, los quals vingen a la caxa de la dita confraria per a cera, e a les necessitats de la dita confraria, e si serà dia feyner paguen un diner, si ja los dits confrares justa excusació no daràn a coneguda dels majorals de la dita confraria, e aquells puixen absol- 

Rey.

[3] Item, que cascún confrare e confraressa quant iràn al soterrar e acompanyar algún cos de confrare, hajen de portar cascú lum encesa de la casa de hon partiràn ab lo cos fins a la sglesia e de la sglesia fins al simenteri, e fins lo cos sia soterrat, e en la missa tot lo segrat Evangeli, e de la sacra fins haver consumit lo sagrat cos de Jesu //[fol. 239 $\left.v^{\circ}{ }^{\circ}\right]$ Christ nostre redemptor. Plau al Senyor Rey.

[4] Item, que quant algún confrare morra haja de dar de sos bens a la dita confraria tres sous, si major suma no y voldrà dar, e si serà pobre que no pague res, coneguda la dita pobresa per los dits majorals de aquella, a si algú en la sua fi volrà entrar en la dita confraria pague deu sous si major suma no y volrà donar. Plau al Senyor Rey.

[5] Item, que cascún divendres tots los confrares en for de consciencia sien tenguts dir cinch Pater Nostres e set Ave Maries a honor e reverència de la passió de Jesu Christ per les ànimes de les confrares, e cascún disapte set Pater Nostres e set Ave Maries a honor e reverència dels set goigs de nostra dona la gloriosa Verge Maria. Plau al Senyor Rey.

[6] Item, que la casa dedicada per la dita confraria hon se hauràn ajustar los confrares per a les coses necessaries e concernents la conservació e utilitat e augment de la dita confraria, e tenir la caxa, joyes, robes, e altres coses necessaries a la dita confraria, sie la capella major, - la sglesia major de la Verge Maria de la dita vila, en lo loch pus decent hon la dita confraria és fundada sots la dita invocació, per què sie en augment de la dita sglesia. Plau al Senyor Rey.

[7] Item, si algún confrare serà constituit en necessitat, e serà persona que a sa tal necessitat no porà suplir, que la dita confraria a coneguda dels majorals de la dita confraria e de deu consellers de la dita confraria sie //[fol. $\left.240 \mathrm{r}^{\circ}\right]$ ajudat e subvengut axí en les malalties com altres necessitats juxta les facultats de la dita confraria. Plau al Senyor Rey.

[8] Item, que tots aquells qui volràn ésser confrares de la dita confraria per obs de les necessitats de aquella hajen pagar e paguen de entrada tres sous cascún confrare, les quals quantitats vinguen e sien posades en una caxa, la qual caxa haja de tenir claus, a saber es tres diverses, e cascuna clau tinga son majoral, la qual caxa no.s puixa obrir per niguna necessitat urgent o voluntaria sens presencia de deu confrares de la dita confraria que seràn elets per consellers dels dits majorals e la major part de aquells. Plau al Senyor Rey.

[9] Item, que cascún any se puixen ajustar en la sglesia major de la Verge Maria de la dita vila tots los confrares de la dita confraria tantes 
vegades quantes sera necessari per obs de la dita confraria, si tal necessitat hi eccerrerà en benefici de aquella a laor de nostre senyor Déu e servey de sa altesa del Rey nostre senyor, convocant aquells los majorals de la dita confraria, e no en altra manera. Plau al Senyor Rey, pus hi sie en la dita congragació un official real.

[10] Item, que quatre festes del any, çò es de la Annunciació de la Verge Maria de març, lo dia de la Assumció de la Verge Maria, lo dia de la Verge Maria de setembre, e lo dia de la Expectació de nostra senyora, après les vespres dites, tots les confrares $/ /[\mathrm{fo} / .240 \mathrm{v}$. $]$ se hajen de ajustar en la dita yglesia de la Verge Maria hon puixen parlar de les coses concernents la utilitat de la dita confraria e necessitats de aqueIla, e cascún confrare haje de dar les dites quatre festes dos diners cascuna de les dites festes, les quals quantitats sien posades en la dita caxa per obs de la conservació de la dita confraria segons en lo desús dit vuyte capitol se conte parlant de la dita caxa. Plau al Senyor Rey, però que en lo dit ajust haja entrevenir un official real com dit és.

[11] Item, que lo dia de la Assumpció de la Verge Maria, ans del offici sia feta processó solemne per los lochs que s'acostumen les processons ab tots los confrares ab ciris cremants en les mans. Plau al Senyor Rey.

[12] Item, que obtesa la licència de la real majestat per a fundar la dita confraria, que sien elets per los justícia e jurats de la dita vila tres bons homens vehins de la dita vila en majorals de la dita confraria, e per los dits justícia e jurats sien elets deu bons homens dels confrares de la dita confraria per consellers dels dits majorals, e en les altres eleccions fahedores de aquí avant dels dits majorals sie servada aquesta forma, ço és, que la vespra de la Asumpssió de la Verge Maria per los majorals de la dita confraria sien elets treze bons homens e de sana consciencia, a saber es, quatre per cascú dels dits majorals, e hu per le scriva de la dita confraria, los quals ans de fer la dita elecció en presencia dels dits deu consellers de la dita confraria juren que faràn bona e sana elecció segons Déu e sa consciència, e feta la elecció de les dites treze persones dels dits confrares, les noms de aquells sien posats en redelíns de cera, e closos sien posats en un bací plé $/ /[\mathrm{fo} / .241$ $r .{ }^{\circ}$ ] d'aygüa e sien trets dels dit bací tres dels dits redolíns per un infant, e aquells sien majorals aquell any, e los deu que restaràn en lo dit bací sien consellers de aquells en le que los dits majorals los hauran menester, e axi se seguesca perpetualment. Plau al Senyor Rey.

[13] Item, que tots los confrares sien scrits en un libre, e aquell stigue en poder del scriva de la dita confraria per que quant algú voldrà entrar en la dita confraria sie continuat e scrit en lo dit libre, e si algú morrà li sie feta la creu, empero no sie atmes a confrare nigú sino per 
los dits majorals e aquels presents sie scrit en lo dit libre e axí se haurà notícia dels dits confrares quants seràn. Plau al Senyor Rey.

[14] Item, que los dits majorals no hajen salari ni[n]gú ni los consellers, sino que ob reverentiam Dei tinguen la dita majordomia ni puixen donar ni guastar en dinars ni sopars ni col.lacions cosa alguna sino tantum en les necessitats de la dita confraria e dels confrares de aqueIla constituits en necessitats en la forma ja desús dita. Plau al Senyor Rey.

[15] Item, si en los presents capítols hi haurà algúns capítols ab paraules ambigües o dubtoses, aqueles sien interpretades e declarades per los majorals a consell de un doctor de bona e sana consciència. Plau al Senyor Rey.

[16] Item, per què lo succés del temps mostra la necessitat de les coses, si en los presents capítols se haurà de smenar alguna cosa o de nou //[fol. $\left.241 \mathrm{v} .^{\circ}\right]$ fer o ajustar alguns altres capítols, o conmutar en millor, que sien a servey de nostre senyor Déu e conservació de la dita confraria, los dits confrares los puixen fer conmutar e ajustar e de nou smenar ab auctoritat e decret del governador del Regne de València o del lochtinent de governador de ça lo riu de Xùquer, e no sens decret de aquells o de l'altre d'ells. Plau al Senyor Rey.

[17] Item, que los dits majorals sien tenguts de fer libre de dates e rebudes, e hajen de dar compte e rahó de sa administració cascún any, lo sendemà del dia de la Assumpció de la Verge Maria, als nous majorals en presencia dels deu consellers de la dita confraria, e donat lo dit compte reten les claus, caxa, diners, robes, joyes e altres coses de la dita confraria als dits nous majorals ab inventari e axis segueixca cascún any de uns en altres perpetualment. Plau al Senyor Rey.

Quequidem capitula preinserta per nos diligenter visa et recognita consulto decretavimus et modifficavimus ipsa ut in pede uniuscuiusque ipsorum capitulorum annotatum est fuerit que ex inde pro parte vestri predictorum justitie juratorum et concilii dicte ville de Alcoy maiestati nostre humiliter suppicatum ut ipsa capitula et ordinationes in eisdem contentas et expressas laudare approbare confirmare et auctorizare de nostri solita benignitate dignaremur. Nos vero prospicientes quantum confert utilitati rei publice huius ville ut in prospero reformetur et conservetur statu. Id circo supplicationi //[fol. $\left.242 r .{ }^{\circ}\right]$ vestre predicte benigniter inclinati volentes quod preinserta capitula omniaque et singula et eorum quolibet contenta teneantur et observentur ab omnibus iuxta responsiones et decretationes nostras in pede uniuscuiusque dictorum capitulorum annotatas.

Tenore presentis nostri privilegii perpetuo firmiter valituri scienter deliberate et consulto capitula preinserta et omnia et singula in eis et 
eorum quolibet contenta iuxta decretationes responsiones et modificationes in pede uniuscuiusque eorum continuatas ut superius continetur laudamus approbamus confirmamus et concedimus eisque auctoritatem nostram impendimus pariter et decretum. Illustrissimo propterea Joanni principi Asturiarum et Gerunde primogenito nostro carissimo ac in omnibus regnis et terris nostris post felices et longevos dies nostros inmediate heredi et succesori intentum nostrum aperientes sub paterne benedictionis obtendu dicimus gerentiquoque vices nostri generalis gubernatoris in dicte Valentie regne baiule generali justitiis juratis ceterisque demum universis et singulis officialibus et subditis nostris in eodem regne constitutis et constituendis diotorumque officialium locuntenentibus dicimus precipimus et iubemus sub ire et indignationis nostre in cursu penaque florenorum auri Aragonum duorum mille a secus agentis bonis exigendorum nostrisque inferendorum erariis quatenus predicta capitula et omnia et singula in eis et ipsorum quolibet et contenta firmiter //[fol. $242 \mathrm{v}$. ${ }^{9}$ et observent tenerique et observari faciant inviolabiliter per quoscumque et non contrafaciant vel veniant ratione aliqua sine causa pro quanto illustrissimus princeps nobis obedire ceterique autem officiales et subditi nostri gratiam nostram caram habent iramque et indignationem nostras ac preapositam penam cupiunt non subire.

In cuius rei testimonium presentem fieri iussimus nostro comuni sigillo impendenti munitum.

Datum in civitate Segovie quarto die mensis augusti anno a Nativitate Domini millesimo quadringentesimo nonagesimo quarto regnorumque nostrorum videlicet Sicilie anno vicesimo septimo Castelle et Legionis vicesimo primo Aragonum et aliorum sexto decimo Granate autem tertio.

Yo el Rey

Dominus Rex mandavit mihi Ludovico Gonçales vissa per Albanell regis cancellarii generalem thesaurarii et per Malferitum de regio consilio et per A. Bonet pro generali conservatore.

Probata 